\title{
Extracorporeal membrane oxygenation for severe respiratory failure in newborn infants (Review)
}

\author{
Elbourne D, Field D, Mugford M
}

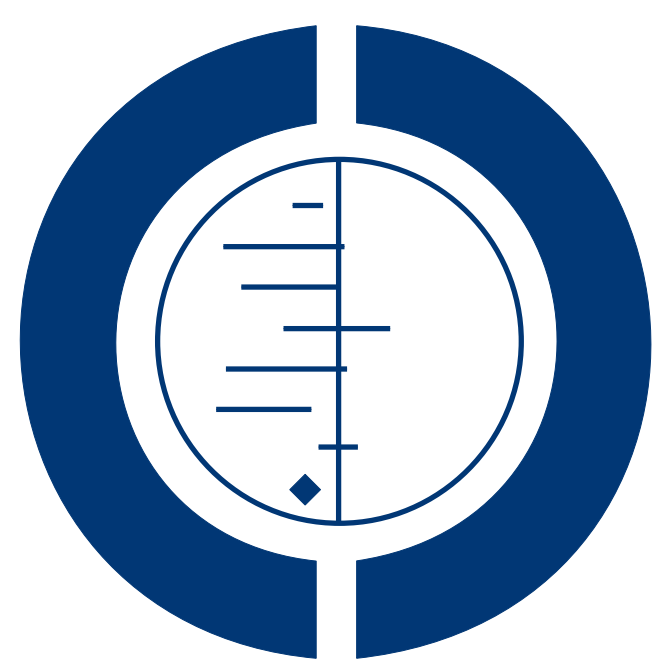

\section{THE COCHRANE COLLABORATION $^{\circledR}$}

This is a reprint of a Cochrane review, prepared and maintained by The Cochrane Collaboration and published in The Cochrane Library 2002, Issue 1

http://www.thecochranelibrary.com

\section{WILEY}

Extracorporeal membrane oxygenation for severe respiratory failure in newborn infants (Review)

Copyright $\odot 2008$ The Cochrane Collaboration. Published by John Wiley \& Sons, Ltd. 
TABLE OF CONTENTS

HEADER . . . . . . . . . . . . . . . . . . . . . . . . . . . . . . . . . . . . . . . . 1

ABSTRACT . . . . . . . . . . . . . . . . . . . . . . . . . . . . . . . . . . . . . . . . 1

PLAIN LANGUAGE SUMMARY . . . . . . . . . . . . . . . . . . . . . . . . . . . . . . . . . . . 2

BACKGROUND . . . . . . . . . . . . . . . . . . . . . . . . . . . . . . . . . . . . . .

OBJECTIVES . . . . . . . . . . . . . . . . . . . . . . . . . . . . . . . . . . . . . .

RESULTS . . . . . . . . . . . . . . . . . . . . . . . . . . . . . . . . . . . . . . .

DISCUSSION . . . . . . . . . . . . . . . . . . . . . . . . . . . . . . . . . . . . . . 4

AUTHORS' CONCLUSIONS . . . . . . . . . . . . . . . . . . . . . . . . . . . . . . . . 4

ACKNOWLEDGEMENTS . . . . . . . . . . . . . . . . . . . . . . . . . . . . . . . . . 5

REFERENCES . . . . . . . . . . . . . . . . . . . . . . . . . . . . . . . . . . . . . 5

SOURCES OF SUPPORT . . . . . . . . . . . . . . . . . . . . . . . . . . . . . . . . . . . . . . .

INDEX TERMS . . . . . . . . . . . . . . . . . . . . . . . . . . . . . . . . . . . . 6

Extracorporeal membrane oxygenation for severe respiratory failure in newborn infants (Review)

Copyright $\odot 2008$ The Cochrane Collaboration. Published by John Wiley \& Sons, Ltd. 


\title{
[Intervention Review] \\ Extracorporeal membrane oxygenation for severe respiratory failure in newborn infants
}

\author{
D Elbourne, D Field, M Mugford
}

Contact address: Prof Diana Elbourne, Head of Unit, Reader in Health Care Evaluation, Room 129, Medical Statistics Unit, London School of Hygiene and Tropical Medicine, Keppel Street, London, WC1E 7 HT, UK. diana.elbourne@lshtm.ac.uk.

Editorial group: Cochrane Neonatal Group.

Publication status and date: Unchanged, published in Issue 2, 2008.

Review content assessed as up-to-date: .

Citation: Elbourne D, Field D, Mugford M. Extracorporeal membrane oxygenation for severe respiratory failure in newborn infants. Cochrane Database of Systematic Reviews 2002, Issue 1. Art. No.: CD001340. DOI: 10.1002/14651858.CD001340.

Copyright (C) 2008 The Cochrane Collaboration. Published by John Wiley \& Sons, Ltd.

\begin{abstract}
A B S T R A C T

\section{Background}

Extracorporeal membrane oxygenation (ECMO) is a complex procedure of life support in severe but potentially reversible respiratory failure, used particularly in mature newborn infants. Although the number of babies requiring ECMO is small, and the ECMO policy invasive and potentially expensive, its benefits may be high.
\end{abstract}

\section{Objectives}

To determine whether ECMO used for neonatal infants with severe respiratory failure is clinically effective and cost-effective compared to a policy of conventional ventilatory support.

\section{Search strategy}

The Cochrane Neonatal Group Specialised Register, the Cochrane Controlled Trials Register, and MEDLINE were searched for 1974 to 2001 .

\section{Selection criteria}

All randomised trials comparing neonatal ECMO to conventional ventilatory support.

\section{Data collection and analysis}

The authors independently evaluated the trials for methodological quality and appropriateness for inclusion in the Review (without consideration of their results), and then independently extracted the data.

\section{Main results}

The three trials from the USA and one from the UK recruited clinically similar groups of babies. Two trials excluded infants with congenital diaphragmatic hernias. In two, transfer for ECMO implied transport over a considerable distance. One study included an economic evaluation. Two trials had follow up information.

All except the UK trial had very small numbers of patients. Two of the trials used conventional randomisation with low potential for bias. The other two used less usual designs which have led to difficulties in their interpretation.

All four trials showed a strong benefit of ECMO on mortality (RR 0.44; 95\% CI 0.31 to 0.61 ), especially for babies without congenital diaphragmatic hernia (RR 0.33 , 95\% CI 0.21 to 0.53 ). Only the UK trial provided information about death or disability at one and 
four years, and showed benefit of ECMO at one year (RR 0.56, 95\% CI 0.40 to 0.78 ), and at four years (RR 0.62 , $95 \%$ CI 0.45 to 0.86). Overall nearly half of the children had died or were severely disabled at four years of age, reflecting the severity of their underlying conditions. Based on economic analysis from the UK trial, the ECMO policy is as cost-effective as other intensive care technologies in common use.

\section{Authors' conclusions}

A policy of using ECMO in mature infants with severe but potentially reversible respiratory failure would result in significantly improved survival without increased risk of severe disability amongst survivors. For babies with diaphragmatic hernia ECMO offers short term benefits but the overall effect of employing ECMO in this group is not clear.

Further studies are needed to refine ECMO techniques; to consider the optimal timing for introducing ECMO; to identify which infants are most likely to benefit; and to address the longer term implications of neonatal ECMO during later childhood and adult life.

\section{PLAIN LANGUAGE S MMARY}

Synopsis pending.

\section{B A C K G R O U N D}

Extracorporeal membrane oxygenation (ECMO) is a complex technique for providing life support in severe but potentially reversible respiratory failure. The technique oxygenates blood outside the body, obviating the need for gas exchange in the lungs and, if necessary, provides cardiovascular support. It is most commonly used to support mature newborn infants, as preterm infants are not suitable both because of the size of the cannulae required, and because of their additional risk of intraventricular haemorrhage associated with the use of heparin.

The concept arose as an off-shoot of cardiopulmonary by-pass technology. Initially it was used to support adults but early results were poor. Similarly, early attempts to use ECMO in the treatment of newborns were unsuccessful; cannula problems provided the greatest technical difficulty. However in 1975 Bartlett reported the first mature newborn treated successfully with ECMO and other reports soon followed (Bartlett 1976). It subsequently became clear that mature infants with persistent pulmonary hypertension of the newborn (PPHN) were particularly suited to ECMO since the better oxygenation and physiological stability produced by ECMO improved pulmonary blood flow without the risk of further barotrauma.

ECMO is an extremely invasive and technically involved procedure. Traditional ECMO uses two large gauge catheters, one placed in a central vein and the other in a central artery (venoarterial or $\mathrm{V}$-A). It is essential to achieve adequate flow rates (approximately $100-120 \mathrm{mls} / \mathrm{kg} / \mathrm{min}$ ) and as a result cannulae are normally 12 - 14 French gauge. Blood is drained passively via the venous catheter which is inserted into the internal jugular vein and positioned in the right atrium. Blood then passes on to a pump which maintains flow in the circuit. A 'bladder box' and servo system prevent the pump from working if venous drainage becomes inadequate for any reason. Blood then passes to an oxygenator where a sweep gas passes in counter current to the blood. The concentration of oxygen in the sweep gas can be adjusted depending on the needs of the patient. Before re-entering the body warming occurs in a heat exchange column. Blood is returned via the common carotid artery at systemic pressure. This type of ECMO is able to support both pulmonary and cardiac function. More recently veno-venous (V-V) ECMO, which provides just pulmonary support, has become popular. The particular, theoretical, advantage of V-V ECMO is that the cerebral arterial blood supply is not disrupted.

Whilst on ECMO additional gas exchange by the lungs is not essential and therefore ventilation is normally reduced to 'rest' settings. This is typically $5-10 \mathrm{~cm} \mathrm{H} 2 \mathrm{O}$ positive end expiratory pressure and 10 to 20 breaths per minute but the approach does vary from centre to centre. This strategy prevents any further lung damage secondary to barotrauma but arrests the atelectasis which might follow acute withdrawal of respiratory support and enhances clearance of secretions.

The point in an individual baby's course at which ECMO should be considered is debatable. A variety of physiological and clinical parameters have been used. However, over time, oxygenation index (OI) of greater than 40 has probably become the most widely 
employed, where

$\mathrm{OI}=(\mathrm{Fi} 02) *($ mean airway pressure $\mathrm{cm} \mathrm{H} 20) * 100 / \mathrm{PaO} 2 \mathrm{~mm}$ $\mathrm{Hg}$.

Although the absolute number of babies who reach this level of severity is never likely to be large, the potential benefits of ECMO may be extremely high. The policy is very invasive, however, and because it is so labour intensive, it is likely to be expensive. Hence there is a need for rigorous evaluation of its advantages and disadvantages to guide practice.

\section{O B J E C T IVES}

To determine whether ECMO used for neonatal infants with severe respiratory failure is clinically effective (especially in terms of mortality and childhood disability) compared to a policy of conventional ventilatory support. The policies will also be assessed in terms of their relative resource use and cost-effectiveness.

\section{R E S U L T S}

Very few of the trials provided information about all the planned outcomes, and only the UK and Syracuse trials had any follow up information. Hence very few of the comparisons show data for all the outcomes, either overall, or in the pre-specified subgroups.

Mortality

Death before discharge home (or to the end of data collection) were the only outcomes reported for all four trials. For death before discharge home, each of the four trials showed a strong benefit of ECMO, but as the three US trials were all very small, the size of effect (typical RR 0.44) was overwhelmingly determined by the UK trial and the $95 \%$ CI was very tight (0.31 to 0.61 ), a highly statistically significant benefit $(\mathrm{p}<0.00001)$. This can also be expressed as a difference in rates of -0.32 ( $95 \%$ CI -0.44 to 0.20 ), implying only three babies need to be treated with ECMO rather than conventional ventilation to prevent one death. The situation was similar for deaths to the end of data collection (typical RR $0.50,95 \%$ CI 0.37 to $0.69 ; \mathrm{p}=0.00003$ ), although there were some later deaths in the ECMO arm (from the trials with follow up).

The majority of patients in these trials did not have congenital diaphragmatic hernia as the primary diagnosis either because this was an exclusion criterion (Boston and Syracuse) or because the numbers with this primary diagnosis were relatively small $(1 / 12$ in the Michigan trial and 35/185 in the UK trial). The risk of death by discharge for babies without this diagnosis was reduced even more (typical RR 0.33 , 95\% CI 0.21 to 0.53 ; $\mathrm{p}<0.00001$ ). The results were similar for deaths to the end of data collection (typical RR $0.41,95 \%$ CI 0.27 to $0.63 ; \mathrm{p}=0.00004$ ). Even for the
35 babies in the UK trial with a primary diagnosis of congenital diaphragmatic hernia, the risk of death was reduced (RR 0.72 , 95\% CI 0.54 to $0.06 ; \mathrm{p}=0.03$ ), but only five infants survived to discharge, and only three children survived to four years of age, all in the ECMO arm (17/17 of the infants in the conventional management arm died before discharge).

Death or disability

Only the UK trial provided information about death or disability at one and four years. This again showed an overall benefit of ECMO at one year (RR $0.56,95 \%$ CI 0.40 to $0.78 ; \mathrm{p}=0.006$ ), and at four years (RR $0.62,95 \%$ CI 0.45 to 0.86 ; $\mathrm{p}=0.004$ ). The benefit was even more marked in the subgroup of children who did not have a primary diagnosis of congenital diaphragmatic hernia at trial entry ( $R R$ at one year $0.45,95 \%$ CI 0.28 to $0.72 ; \mathrm{p}=$ 0.009 ), and at four years (RR $0.49,95 \%$ CI 0.31 to 0.77 ; $\mathrm{p}=$ 0.002). The trend towards benefit for the children with congenital diaphragmatic hernia at trial entry was much less marked $(R R$ at one year $0.78,95 \%$ CI 0.61 to $1.00 ; \mathrm{p}=0.05$ ), and at four years (RR $0.89,95 \%$ CI 0.75 to $1.05 ; \mathrm{p}=0.16$ ), with only two children alive and not severely disabled, both in the ECMO arm.

The Oxygenation Index at trial entry was used as a measure of severity. The effect of a policy of ECMO by four years of age was more marked in the less severe stratum of OI 40-60 (death or severe disability at four years RR $0.52,95 \%$ CI 0.31 to 0.85 ; $\mathrm{p}=$ 0.010 ) than the more severe stratum of $\mathrm{OI}>60$ (death or severe disability at four years RR $0.76,95 \%$ CI 0.52 to 1.12 ; $\mathrm{p}=0.16$ ) although the trend is in the same direction.

Disability and impairment

Data from the UK trial at one year showed no clear trend in relation to the risk of disability or impairment. Assessment of children at one year is difficult to interpret and hence developmental assessments are likely to have lacked precision. At 4 years much more detailed information was available. Five children were lost to follow up ( 3 in the conventional management group). Of the 60 randomised to ECMO and assessed at 4 years, 12 appeared normal and 18 had signs of impairment without disability. The remaining 30 had signs of disability ( 3 severe). In the conventional arm 35 children were assessed, of whom 4 appeared normal with 9 having signs of impairment without disability. The other 22 children in this group were disabled but none were considered severe. The data did not suggest that an increased risk of particular types of adverse neurodevelopmental outcome (eg hemiplegia) was associated with either group.

Use of health services

Measures of resource use are analysed as continuous variables. All four studies reported one or more of the defined resource use outcomes, but the three American studies provided this information for survivors only. In the UK trial, data were reported as medians (interquartile ranges (IQR)). These showed that a policy of 
ECMO compared to CM led to more days on ECMO (4 (3-7) vs 0$)$; more days on a ventilator (2 (0.5-4) vs $0(0-5))$; more days on supplemental oxygen $(3(0-12.5)$ vs $0(0-5))$; fewer days on oxygen at $>90 \%(0.5(0.5-1)$ vs $2(1-5))$; more days in hospital before first discharge home or death (6 (1-11) vs $0.5(0-6))$; and fewer hospital readmissions during the first year $(0(0-3)$ vs 1 ( 0 7)). Some of the greater resource use in the ECMO arm is because of the increased survival.

Costs and cost effectiveness

Only one study (UK 1996) included costs of health care over the year, and this was reported separately (Roberts TE et al 1998). The median cost/case for patients receiving extracorporeal membrane oxygenation was $£ 15276$ (IQR $£ 11242-£ 24786$ ) (mean $£ 20,826$ ) versus $£ 3702$ (IQR 2314-£9649) (mean $£ 7,002$ ) for patients receiving conventional treatment (1994-95 UK sterling prices). When compared to the gain in survival, the additional cost per additional survivor at one year was $£ 51,222$, and the additional cost per additional survivor without severe disability was $£ 75,327$. Sensitivity analysis for uncertainty about transport costs, staffing levels in neonatal and ECMO units, and odds of survival, found that the range of cost per additional survivor could be between $£ 34,346$ and $£ 110,593$. The purchasing power parity between UK£ to US\$ in 1996 was $£ 0.644 \mathrm{~GB}=\$ 1 \mathrm{US}$ (OECD 2001).

\section{DISCUSSION}

There was clear benefit for the ECMO policy in terms of reducing mortality and, although there were some later deaths in the ECMO arm, the balance of benefits remains strongly in favour of the ECMO policy for this outcome. Although there was a nonstatistically significant tendency towards more disability in the ECMO group at one year, this was no longer the case by four years of age in the UK trial. There was also an important benefit of ECMO when considering the composite outcome of death OR severe disability at both one and four years of age. Fuller details of other outcomes from the UK trial shown in the accompanying figures do not alter these conclusions, although numbers of children with any one specific adverse outcome are small.

The diagnosis of severe but potentially reversible respiratory failure is not straightforward. Over the time that ECMO has been available a variety of indices have been used in this role. All are intended to identify babies with a high probability of death from continued conventional therapy. The results of this review would indicate that they achieve this aim. The various measures used to identify suitable infants have not been compared but this seems unnecessary given the randomised nature of the subsequent studies.

The invasive nature of ECMO has been the cause of much concern. The potential for acute problems related to the ECMO circuit and the inevitable disruption to the cerebral circulation led many to make the broad assumption that there was an inherent risk attached to the use of ECMO which would inevitably result in increased morbidity. These concerns have not been born out. Since the risks are undeniable it would appear that the damaging effect of prolonged exposure to aggressive conventional therapy are even greater. It is important to note that only a minority of all recruited infants could be considered normal survivors at four years. Although ECMO has been considered as a single entity in this comparison there was significant use of the veno venous technique in the UK study whilst this was not the case in earlier trials.

The majority of patients in these trials did not have congenital diaphragmatic hernia as the primary diagnosis either because this was an exclusion criterion (Boston and Syracuse) or because the numbers with this primary diagnosis were small (1/12 in the Michigan trial and 35/185 in the UK trial). Although the balance of benefit was still in favour of the ECMO policy (17/17 of the infants in the conventional management arm died before discharge), by the age of 4 years, 16/18 of those in the ECMO arm had also died or were severely disabled.

There was no evidence that the severity of illness as judged by an OI of 40-60 or over 60 affected the benefit of the ECMO policy.

Although there is a clear benefit for the ECMO policy, overall nearly half of the children had died or were severely disabled at four years of age, reflecting the severity of their underlying conditions. Nevertheless, based on the economic analysis from the UK trial (Roberts et al, 1998), the ECMO policy is not only clinically effective but also as cost-effective as other intensive care technologies in common use.

\section{AUTHORS' CONCLUSIONS}

\section{Implications for practice}

A policy of using ECMO in mature infants with severe but potentially reversible respiratory failure would result in significantly improved survival without any increased risk of severe disability amongst survivors. A variety of indices can be used to define such infants but the use of an oxygenation index of 40 seems the most straightforward.

The situation for babies with diaphragmatic hernia is less clear since, despite their common underlying anomaly, they do not represent a homogeneous group. It would appear that ECMO offers short term benefits but the overall effect of employing ECMO in this group is not clear. In the absence of a definitive study the use of ECMO can only be recommended on clinical grounds i.e. where it can be used to stabilise a baby thought to be potentially viable but failing more conventional support.

Cost effectiveness is sensitive to the organisation of health care for ECMO and intensive neonatal care. Lower cot occupancy and 
higher staff to cot ratios increase costs, as do long travel times and distances.

\section{Implications for research}

Further studies are needed to refine ECMO techniques in an attempt to reduce both short term risks (such as circuit failure) and the damage that might result from physiological disruption. A formal comparison of veno venous and veno arterial ECMO seems particularly important in this regard.

The identification of suitable infants also merits further consideration. At present infants are referred for ECMO when other therapies have failed and the baby is continuing to deteriorate. Outcomes might be improved by introducing ECMO earlier, ie as soon as all other therapies have failed.

The longer term effects of neonatal ECMO (eg during later childhood, adolescence and adult life) remain unclear. Studies to ad- dress these issues are clearly important if infants are going to continue to be offered this form of life support. A seven year follow up is in progress for the UK trial.

The correct approach to the management of infants with diaphragmatic hernia is not known. Large randomised studies, with long term follow up, are needed in order to establish both the best approach to acute management and the extent to which "normal survival" is achievable with our present treatment options. There is some uncertainty about what constitutes "present treatment options" and establishing the test arms would clearly be the first step in developing such a study.

\section{ACKNOWLEDGEMENTS}

Ellen Bifano, and Ann Johnson, Charlotte Bennett and Carole Harris for unpublished data.

\section{R E F E R E N C E S}

\section{References to studies included in this review}

\section{Boston 1989 \{published data only\}}

O’Rourke PP, Crone RK, Vacanti JP, Ware JH, Lillehei CW, Parad RB, Epstein MF. Extracoporeal membrane oxygenation and conventional medical therapy in neonates with persistent pulmonary hypertension of the newborn: A prospective randomized study. Pediatrics 1989;84:957-63.

Michigan 1985 \{published data only\} Barlett RH, Roloff DW, Cornell RG, Andrews AF, Dillon PW, Zwischenberger JB. Extracorporeal circulation in neonatal respiratory failure: A prospective randomized study. Pediatrics 1985;76:479-87.

Syracuse 1992 \{published and unpublished data\}

* Bifano EM, Hakanson DO, Hingre RV, Gross SJ. Prospective randomized controlled trial of conventional treatment or transport for ECMO in infants with persistent pulmonary hypertension (PPHN). Pediatr Res 1992;31: 196A.

Gross SJ, Bifano EM, D’Eugenio D, Hakanson DO, Hingre RV. Prospective randomized controlled trial of conventional treatment or transport for ECMO in infants with severe persistent pulmonary hypertension (PPHN): two year follow up. Pediatr Res 1994;36:17A.

UK 1996 \{published data only\}

Bennett C, Johnson A, Field D, Elbourne D for UK Collaborative ECMO trial group. UK collaborative randomised trial of neonatal extracorporeal membrane oxygenation: follow up to age 4 years. Lancet 2001;357: 1094-6.

Roberts $\mathrm{T}$ and the Extracorporeal Membrane Oxygenation Economics Working Group. Economic evaluation and randomised controlled trial of extracorporeal membrane oxygenation: UK Collaborative Trial. BMJ 1998;317: 911-16.

UK Collaborative ECMO Trial Group. The Collaborative UK ECMO Trial: Follow-up to 1 year of age. Pediatrics (URL: http://www.pediatrics.org/cgi/contents/full/101/4/ e1) 1998; Vol. 101, issue 4.

* UK Collaborative ECMO Trial Group. UK collaborative randomised trial of neonatal extracorporeal membrane oxygenation. Lancet 1996;348:75-82.

\section{Additional references}

\section{Bartlett 1976}

Bartlett RH, Gazzaniga AB, Jefferies MR, et al.Extracorporeal membrane oxygenation (ECMO) cardiopulmonary support in infancy. Trans Am Soc Artif Intern Organs 1976;22:80-93.

Drummond 1996

Drummond MF, Jefferson TO. Guidelines for authors and peer reviewers of economic submissions to the BMJ. The BMJ Economic Evaluation Working Party. BMJ 1996;313: 275-83.

\section{OECD 2001}

Organisation for Economic Cooperation and Development. Main economic indicators. http://wwwl.oecd.org October 2001.

\section{Zelen 1979}

Zelen M. A new design for randomized clinical trials. $N$ Eng J Med 1979;300:1242-1245.

* Indicates the major publication for the study 
SOURCES OF SUPPORT

\section{External sources of support}

- No sources of support supplied

\section{Internal sources of support}

- No sources of support supplied

\section{INDEX TERMS}

\section{Medical Subject Headings (MeSH)}

*Extracorporeal Membrane Oxygenation; Infant, Newborn; Randomized Controlled Trials as Topic; Respiratory Insufficiency [*therapy]

\section{MeSH check words}

Humans 